\title{
PERANAN PUBLIC RELATIONS DALAM MENJARING PEMASANG IKLAN PADA RADIO REPUBLIK INDONESIA CABANG MADYA - DENPASAR
}

\author{
I Dewa Ayu Hendrawathy Putri \\ Jurusan Ilmu Komunikasi, Fakultas Dharma Duta, Institut Hindu Dharma Negeri (IHDN) \\ Denpasar Bali
}

\begin{abstract}
ABSTRAK
RRI sebagai salah satu unit pelayanan teknis pemerintah di bidang jasa penyiaran, sejalan dengan tingkat perkembangan dan kemajuan pelayanan, perlu memiliki landasan kerja guna meningkatkan dan menjamin mutu pelayanan jasa penyiarannya. Public Relations yang merangkap bagian divisi Pemasaran dan Pembangunan Usaha secara struktural berada di bawah pimpinan perusahaan. Pada bagian divisi Pemasaran dan Pembangunan Usaha hanya terdiri dari sepuluh orang dan semuanya berperan penting menjadi seorang PR yang mampu mempromosikan RRI. PR diberi wewenang untuk menjalankan tugas sebaik-baiknya khususnya dalam menjalin hubungan dengan pemasang iklan agar dapat meningkatkan kepercayaan masyarakat untuk memasangkan iklan khususnya bagi masyarakat pendengar. Team kerja PR dituntut untuk berkreativitas dalam mempromosikan dan memasangkan produk perusahaan sesuai dengan tugasnya masing-masing. Dengan cara demikian PR dapat terlaksana dengan baik dan lancar sehingga dapat tercapainya tujuan perusahaan. Kegiatan PR juga berupaya untuk mewujudkan hubungan yang harmonis antara badan usaha atau organisasi dengan publiknya. Hal ini dilakukan untuk menarik perhatian pemasang iklan untuk memasangkan iklannya, usaha untuk menanamkan kesan yang menyenangkan, sehingga timbul opini publik yang menguntungkan bagi kelangsungan hidup perusahaan. Sikap yang simpatik, ramah dan sopan yang menunjukkan perhatian terhadap publik akan menciptakan suatu kerja sama yang baik antara Public Relations dengan para pemasang iklan sehingga dapat menghasilkan kerja sama yang profesional.
\end{abstract}

Kata-kata kunci: Public Relations, penyiaran, pemasaran, iklan

\section{THE PUBLIC RELATIONS ROLE IN PERSUADING ADVERTISERS IN RADIO OF THE REPUBLIC OF INDONESIA MADYA BRANCH - DENPASAR}

\begin{abstract}
$\boldsymbol{R} \boldsymbol{R}$ I as one of government technical services unit in broadcasting services, in line with the level of service development and advancement, needs to have a working foundation to improve and to ensure the quality of its broadcasting services. Public Relations and Marketing division merged structurally in marketing and business development division. The division of Marketing and Business Development consists of ten people, which plays an important role as a PR and have the capability of promoting RRI. PR is authorized to perform the best they can, especially in relation to advertisers, which will be able to improve public trust especially the listeners. PR work team is required to produce creativity in promoting the company's products as their duties. In this way PR objectives can be done properly and smoothly to achieve the company's goals. PR activity also seeks to create a harmonious relationship between the business or organization's publics. This is done to persuade advertisers to place their ads and an attempt to establish good impression, which raised public opinion in favor of the company' continuation. Sympathetic attitude, friendly and courteous attention to the public will create a good link between Public Relations with advertisers so that they can establish a professional cooperation.
\end{abstract}

Keywords: Public Relations, broadcasting, marketing, advertising

Korespondensi: I Dewa Ayu Hendrawathy Putri, S.Sos, M.Si. Jurusan Ilmu Komunikasi, Fakultas Dharma Duta, Institut Hindu Dharma Negeri (IHDN), Jalan Ratna No.51, Denpasar, Bali. Email: ayuhendra_1975@yahoo.co.id 


\section{PENDAHULUAN}

Dalam meningkatkan daya saing di bidang pelayanan jasa penyiaran kepada masyarakat pada era globalisasi, sangat perlu menentukan satuan kerja instansi pemerintah menjadi badan usaha pelayanan secara mandiri dan otonom mengelola instansinya. RRI sebagai salah satu unit pelayanan teknis pemerintah di bidang jasa penyiaran, sejalan dengan tingkat perkembangan dan kemajuan pelayanan, perlu memiliki landasan kerja guna meningkatkan dan menjamin mutu pelayanan jasa penyiarannya.

Untuk kelancaran dan terjaminnya pelaksanaan dan pengelolaan RRI secara ekonomis, guna memberi manfaat sebesarbesarnya bagi masyarakat, bangsa dan negara. Maka perlu mengalihkan status Radio Republik Indonesia menjadi badan usaha pelayanan yang memiliki kewenangan otonomi yang lebih luas. Berhasil tidaknya suatu perusahaan didalam mencapai tujuannya sangat tergantung dari kemampuan dalam fungsi-fungsi manajemen Radio Republik Indonesia. Manajemen RRI dalam menjalankan tugasnya dibantu oleh beberapa divisi antara lain Divisi Pemberitaan, Divisi Penyiaran, Divisi Teknik, Divisi Administrasi dan Keuangan, serta Divisi Pemasaran dan Pembangunan Usaha. Sangat diperlukan sinergi kerja dari divisi-divisi tersebut agar organisasi dapat berjalan dengan baik dan lancar. Bagi setiap perusahaan radio baik milik Negara maupun Swasta yang memproduksi siaran pendidikan, hiburan, serta sebagai sarana informasi dan persuasif, pada umumnya mempunyai tujuan yaitu untuk meningkatkan mutu siaran agar siarannya diminati dan didengar oleh masyarakat. Untuk dapat meningkatkan mutu siaran tersebut diperlukan dukungan dana, salah satu sumber dana yang diandalkan oleh RRI berasal dari iklan, dalam hal ini pihak bagian Public Relations harus menyusun perencanaan strategi kerja yang lebih baik agar dapat menarik minat masyarakat untuk memasangkan iklannya di RRI Denpasar, mengingat begitu banyak bermunculan radio swasta di Bali yang juga sangat menarik minat masyarakat untuk mendengarnya sehingga berimbas pada daya saing perebutan iklan.

Public Relations di RRI Cabang MadyaDenpasar ditangani oleh semua bagian Divisi Pemasaran dan Pembangunan Usaha, hal ini dikarenakan Public Relations di RRI Denpasar belum berdiri sendiri atau belum menjadi divisi khusus. Namun pada bagian Divisi PPU merangkap sebagai Public Relations yang memiliki fungsi, tugas serta tujuan yang sama yaitu untuk membangun RRI menjadi lebih maju, karena itu Divisi PPU yang merangkap sebagai PR mempunyai peran yang sangat besar dalam mengenalkan RRI Denpasar kepada masyarakat.

Dalam hal ini Public Relations diperlukan untuk menyusun dan mengevaluasi strategistrategi pemasaran yang efisien dan berorientasi pada tujuan perusahaan. Berdasarkan uraian tersebut maka dapat dikatakan bahwa keberadaan Public Relations dalam suatu perusahaan atau lembaga mempunyai posisi sangat penting untuk menjaga kestabilan suatu perusahaan dan memiliki mutu yang baik. Mengacu pada kondisi di atas, penulis tertarik untuk melakukan penelitian dan penulisan tentang bagaimana peranan Public Relations Radio Republik Indonesia Cabang Madya Denpasar dalam menjaring pemasang iklan.

Berdasarkan uraian pada latar belakang di atas maka persaingan tidak dapat dihindari lagi. Dengan kondisi demikian tentu menuntut Radio Republik Indonesia Denpasar untuk berbuat lebih baik lagi dalam menarik simpati masyarakat untuk memasangkan iklannya di RRI Denpasar.

Maka dalam hal ini sampai pada masalah yang menjadi objek pembahasan yaitu: "Bagaimana peranan Public Relations dalam usaha menjaring pemasang iklan pada Radio Republik Indonesia Cabang Madya - Denpasar".

Setiap langkah penelitian ilmiah sudah tentu mempunyai tujuan seperti dikemukakan oleh Husein Umar (2005: 3) menyebutkan: Tujuan penelitian ilmiah adalah usaha untuk mencapai sasaran yang memiliki kebenaran dengan fakta secara masuk akal. Sedangkan Kartini Kartono (1990: 40) menyampaikan penelitian research bertujuan untuk menemukan, mengembangkan dan menguji kebenaran atau pengetahuan, menemukan disini berarti mendapatkan suatu yang baru untuk mengisi kekurangan dan vakum (kekosongan) akan menciptakan/ menemukan sesuatu yang sebelumnya belum ada.

Adapun tujuan penelitian ini adalah mengulas ulang teori-teori/ penemuanpenemuan ilmiah tentang peranan Public Relations dalam usaha menjaring pemasang iklan di RRI Cabang Madya - Denpasar dan mengupas teori-teori/ penemuan ilmiah tentang Public Relations dalam menjaring pemasang iklan di RRI Cabang Madya - Denpasar.

Secara teoretik, diharapkan penelitian ini 
dapat memberikan kontribusi yang bermanfaat dan positifbagiperkembangan ilmu pengetahuan pada umumnya dan ilmu komunikasi dalam hal ini Public Relations pada khususnya. Sedangkan secara praktis, diharapkan penelitian ini akan menjadi masukan yang sangat berarti dan bermanfaat bagi para praktisi Public Relations khususnya dalam pelaksanaan aktivitas Public Relations dalam menjaring pemasang iklan di RRI Cabang Madya - Denpasar.

\section{METODE PENELITIAN}

Pelaksanaan Fungsi Public Relations mencakup ada tidaknya usaha PR untuk membangun hubungan yang harmonis antara pimpinan dengan karyawan dan antara sesama karyawan, ada tidaknya usaha PR dalam menciptakan kerjasama yang baik diantara karyawan dengan seseorang/ perusahaan yang memasangkan iklan juga terhadap masyarakat, ada tidaknya usaha PR dalam menumbuhkan rasa kepuasan bersama diantara masyarakat yang berkepentingan, ada tidaknya motivasi kerja karyawan dalam rangka meningkatkan kualitas kerja sebagai penopang di bidang pemasaran untuk membantu mempromosikan produk siaran yang ditawarka, ada tidaknya pertemuan rutin yang diadakan setiap bulannya dalam rangka membahas hasil kerja yang sudah dijalankan, dan ada tidaknya rapat diadakan bilamana ada komplain dari perusahaan atau seseorang yang memasangkan iklan.

Sedangkan produktifitas dapat diukur dengan dapat tidaknya penyelesaian tugas sesuai dengan batas waktu yang telah ditentukan, ada tidaknya hasil kerja yang dicapai sesuai dengan hasil program, dapat melaksanakan tugas sesuai job masing-masing, peningkatan disiplin dalam melaksanakan tugas, dan peralatan yang digunakan sesuai metode.

Populasi adalah keseluruhan objek penelitian. Apabila seorang ingin meneliti semua elemen yang ada dalam wilayah penelitian, maka penelitiannya merupakan penelitian populasi. Studi atau penelitiannya disebut studi populasi. (Arikunto, 1997: 108).

Dalam hal ini yang menjadi populasi dalam penelitian ini adalah seluruh staf divisi pemasaran dan pembangunan usaha Perjan RRI Cabang Madya Denpasar, khususnya yang menjaring pemasang iklan. Karyawan Divisi PPU berjumlah 10 orang, yang terdiri dari:

$\begin{array}{ll}\text { Senior Manager } & : 1 \text { orang } \\ \text { Manager } & : 3 \text { orang }\end{array}$
Staf $: 6$ orang

Teknik pengumpulan data dilakukan dengan wawancara, observasi, dan dokumentasi. Wawancara adalah teknik untuk mendapatkan data secara langsung (bertatap muka) dengan pihak yang berkaitan dengan objek yang diteliti. Wawancara dilakukan secara mendalam dengan cara berhadapan langsung. Teknik wawancara yang digunakan adalah bebas terpimpin dan wawancara ini dilakukan pada subjek penelitian per tim khusus (khusus tim Public Relations). Metode ini dimaksudkan untuk mengumpulkan data mengenai tujuan, fungsi, tugas, media dan proses kegiatan PR dalam meningkatkan mutu siaran di perusahaan Jawatan RRI Cabang Madya Denpasar.

Observasi adalah suatu teknik memperoleh keterangan dengan mengadakan pengamatan dan pencatatan secara langsung pada objek penelitian yaitu kegiatan PR dalam rangka meningkatkan mutu siaran. Observasi ini dilakukan untuk melengkapi dengan menambah hasil pengumpulan data melalui wawancara dan dokumentasi.

Dokumentasi adalah suatu teknik mencari data berupa catatan, transkrip buku, surat kabar, majalah, agenda. Metode ini digunakan untuk mengumpulkan data yang berhubungan sejarah organisasi, struktur serta jumlah karyawan dan jabatan.

Dalam menganalisis data, penulis menggunakan analisis deskriptif yaitu metode penalaran dengan mendeskripsikan data-data dalam bentuk keterangan atau penjelasan secara naratif. Langkah-langkah penulis dalam menganalisa data yang diperoleh adalah melalui tahapan pengumpulan data, penyajian data secara sistematik, pembahasan, dan kesimpulan. Pengumpulan data sebagai bahan untuk kajian dalam pembahasan sebuah permasalahan. Penyajian data secara sistematik untuk memberikan gambaran yang konkrit tentang keadaan objek penelitian. Pembahasan dilakukan berdasarkan teoriteori dan kajian dari sumber-sumber yang bisa dipertanggungjawabkan untuk mencapai suatu kesimpulan tentang apa yang menjadi pokok bahasan. Dan terakhir, kesimpulan diambil setelah memperoleh gambaran lengkap tentang objek penelitian sebagai hasil akhir dari penelitian.

\section{HASIL DAN PEMBAHASAN}

RRI Cabang Madya - Denpasar menempati 
bangunan rumah Pemerintah Daerah tahun 1953 RRI membeli tanah seluas $5.510 \mathrm{M}^{2}$ yang berlokasi di Jalan Tanimbar Denpasar, untuk lokasi pemancar dan perumahan, tahun 1959 membeli tanah seluas 3.375 $\mathrm{M}^{2}$ terletak di Jalan Melati 49 Denpasar Denpasar untuk studio dan perkantoran $11,43 \mathrm{M}^{2}$ di Jalan Raya Sanur Klandis Denpasar yang saat ini sebagai studio dan perkantoran RRI Denpasar yang baru. Tahun 1976 membeli tanah seluas 34.478,25 $\mathrm{M}^{2}$ di Latu Abiansemal untuk gedung pemancar, gedung diesel berikut kantor petugas pemancar, yang dilengkapi oleh dua buah rumah jaga. Tahun 1976 RRI Denpasar mendatangkan sebuah pemancar berkekuatan $10 \mathrm{~kW}$. Untuk gelombang MW dan 9 KVA serta sebuah peralatan studio tipe D beserta STLnya. Tahun 1980 tenaga teknik RRI berhasil merakit sebuah pemancar MW dengan kekuatan 100 watt dengan gelombagn 215 meter dan tahun 1982 ditingkatkan menjadi 500 watt dengan gelombang 436 meter bersamaan dengan itu pula dibeli sebuah pemancar FM dan LEM berkekuatan 50 watt (Lima Windu RRI: 23).

Dan di tahun-tahun berikutnya yakni tahun 1990-1997 RRI Cabang Madya-Denpasar mendapat bantuan peralatan: STL, SHF, UNF, VHF STL (FX STL) dari Australia dan alat-alat ini masih digunakan sampai sekarang.

Sampai saat ini RRI Cabang MadyaDenpasar memiliki sebuah struktur organisasi. Struktur organisasi tersebut merupakan kerangka kerja untuk mengetahui bagaimana posisi seseorang dan hubungan dengan orang lain dalam suatu perusahaan. Struktur organsiasi RRI Cabang Madya Denpasar merupakan struktur organisasi garis, yakni struktur organisasi yang memiliki rantai perintah yang jelas dan mengalir ke bawah melalui tingkatantingkatan managerial, dimana tanggung jawab pekerjaan hanya kepada satu atasan. (Struktur organisasi RRI digambarkan pada Gambar 1) .

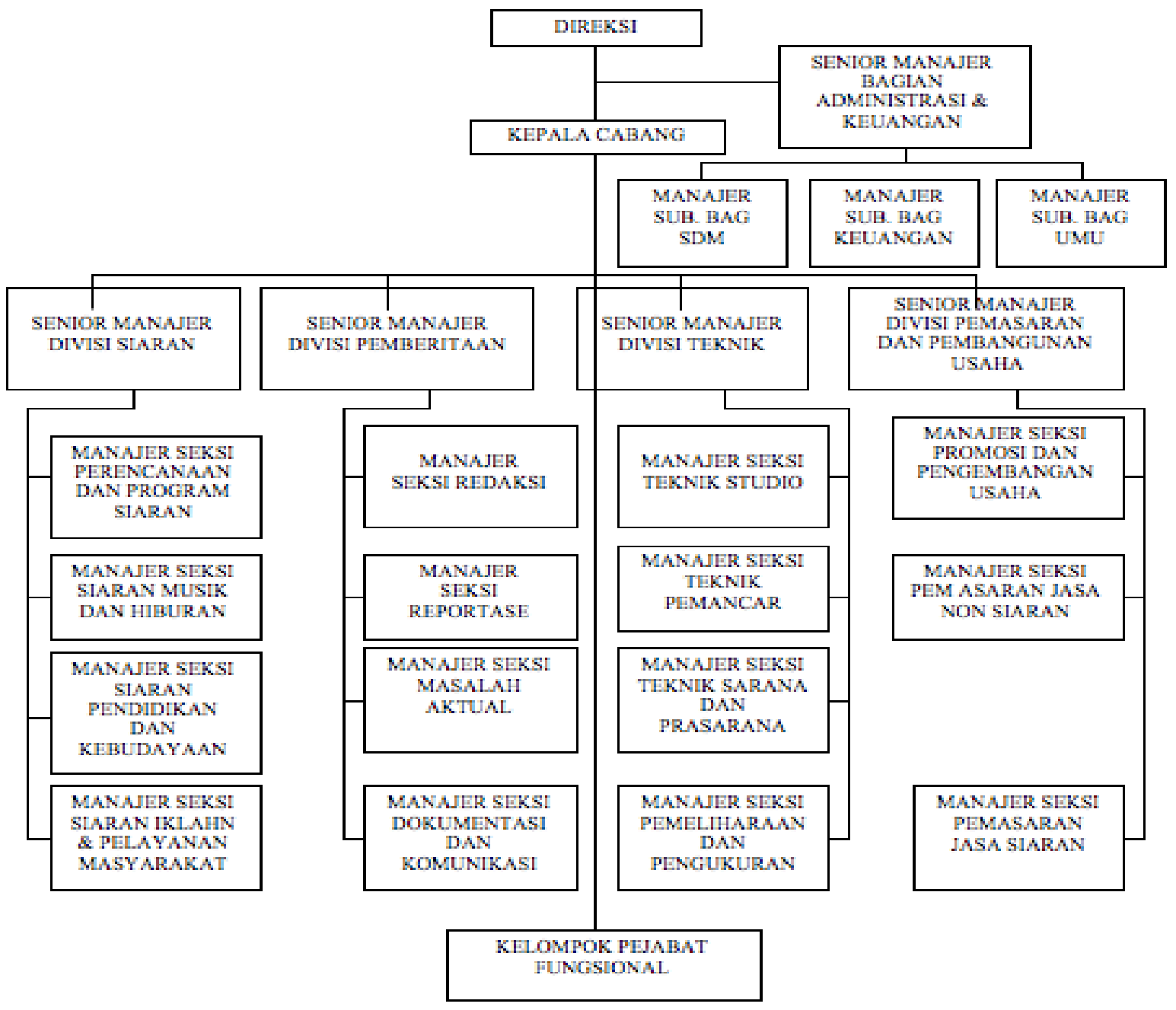

Gambar 1 Bagan Struktur Organisasi Perjan RRI Cabang Madya Denpasar Sumber: RRI Cabang Madya Denpasar 
Terdapat empat seksi seksi di dalam divisi pemasaran dan pembangunan usaha yaitu seksi promosi dan pengembangan usaha, seksi non siaran, seksi pemasaran jasa siaran, dan divisi pemasaran dan pembangunan usaha. Seksi promosi dan pengembangan usaha bertugas untuk (1) Membuat perencanaan strategi pemasaran, publikasi, pengembangan usaha. (2) Mempromosikan dua seksi yaitu seksi siaran dan non siaran, (3) Menggali kerjasama intern dan ekstern untuk keperluan promosi, publikasi, dan pengembangan usaha, data/bahan, deskripsi acara siaran, (4) Menyiapkan profile company (data-data perusahaan), (5) Menghimpun dan mengolah data untuk mengetahui positioning guna pengembangan usaha, (6) Mengumpulkan data untuk keperluan evaluasi.

Seksi non siaran bertugas untuk (1) Membuat perencanaan strategi pemasaran jasa non siaran, (2) Menggali kerjasama intern dan ekstern, untuk jasa non siaran, (3) Membuat rade card pelayanan jasa non siaran, (4) Membuat catatan semua transaksi yang pada seksi pemasaran jasa non siaran sebagai bahan evaluasi, (5) Mengkoordinasikan pelayanan kepada masyarakat dengan unit terkait, dan (6) Membuat laporan pemasaran jasa non siaran. Seksi pemasaran jasa siaran bertugas untuk (1) Membuat perencanaan strategi pemasaran jasa siaran, (2) Menggali kerjasama intern dan ekstern, untuk keperluan pemasaran jasa siaran, (3) Membuat rate card (daftar ratarata/pengguna) jasa siaran, (4) Menyiapkan bahan-bahan untuk pemasaran jasa siaran, (5) Memberikan order kepada pihak-pihak terkait sesuai pesanan klien, (6) Mencatat semua transaksi yang dilakukan melalui pemasaran jasa siaran, sebagai bahan evaluasi, (7) Membuat laporan pemasaran siaran secara periodik, dan (8) Sistem pendistribusian hasil kerjasama berdasarkan prosentase.

Radio RRI Cabang Madya Denpasar adalah radio yang sudah banyak diketahui oleh publik khususnya masyarakat Denpasar, berbagai cara dan daya tarik telah dilakukan RRI dalam berpromosi dengan melakukan pendekatan yang terpadu agar pesan yang disampaikan RRI mudah diingat dan efektif. Dengan melakukan aktifitas Public Relation dalam mendukung promosi RRI yang bertujuan untuk memberikan informasi kepada khalayak ramai maupun melakukan apa yang diterapkan dari Public Relations tersebut.

Public Relations di RRI ditangani oleh semua bagian divisi PPU, hal ini dikarenakan
PR di RRI belum menjadi divisi khusus. Namun pada bagian divisi Pemasaran dan Pembangunan Usaha merangkap bagian PR yang memiliki fungsi, tugas serta tujuan yang sama, karena itu mempunyai peran yang sangat besar dalam mengenalkan perusahaan kepada masyarakat, sehingga harus dituntut agar bisa menjalin hubungan yang baik dengan masyarakat agar dapat meningkatkan kepercayaan terhadap RRI.

Public Relations yang merangkap bagian divisi Pemasaran dan Pembangunan Usaha secara struktural berada dibawah pimpinan perusahaan. Pada bagian divisi Pemasaran dan Pembangunan Usaha hanya terdiri dari sepuluh orang dan semuanya berperan penting menjadi seorang PR yang mampu mempromosikan RRI. PR diberi wewenang untuk menjalankan tugas sebaik-baiknya khususnya dalam menjalin hubungan dengan pemasang iklan agar dapat meningkatkan kepercayaan masyarakat untuk memasangkan iklan khususnya bagi masyarakat pendengar. Team kerja PR dituntut untuk berkreatifitas dalam mempromosikan dan memasangkan produk perusahaan sesuai dengan tugasnya masing-masing. Dengan cara demikian PR dapat terlaksana dengan baik dan lancar sehingga dapat tercapainya tujuan perusahaan.

Kegiatan PR juga berupaya untuk mewujudkan hubungan yang harmonis antara badan usaha atau organisasi dengan publiknya. Hal ini dilakukan untuk menarik perhatian pemasang iklan untuk memasangkan iklannya, usaha untuk menanamkan kesan yang menyenangkan, sehingga timbul opini publik yang menguntungkan bagi kelangsungan hidup perusahaan. Sikap yang simpatik, ramah dan sopan yang menunjukkan perhatian terhadap publik akan menciptakan suatu kerjasama yang baik antara Public Relations dengan para pemasang iklan sehingga dapat menghasilkan kerja sama yang profesional.

Kegiatan Public Relations dalam usaha mempertahankan dan mengembangkan RRI Cabang Madya Denpasar dapat dilihat dari beberapa segi dan ini tergantungdari hubungan Public Relations dengan berbagai pihak yang secara langsung berhubungan dengan RRI Cabang-Madya Denpasar. Selama penulis melakukan penelitian di RRI Cabang-Madya Denpasar banyak yangh penulis simak dari segala aktivitas yang dilakukan oleh PR pada perusahaan tersebut, sehingga mereka dapat dikatakan berperan serta menejemen RRI Cabang-Madya Denpasar. 
Berikut ini penulis akan ketengahan hubungan serta bentuk komunikasi yang dilakukan PR pada RRI Cabang Madya Denpasar dalam kaitannya dengan manajemen untuk mempertahankan dan mengembangkan perusahaan RRI, yang mana dalam hal ini penulis awali dengan penjelasan mengenai kegiatan pada RRI Cabang-Madya Denpasar, kemudian akan diketengahkan pula mengenai peranan Public Relations dalam upaya menjaring pemasang iklan pada RRI Cabang Madya Denpasar, serta apa saja yang menjadi faktor pendukung dan penghambatnya.

Kegiatan Public Relations dalam mempertahankan dan mengembangkan RRI Cabang Madya-Denpasar.

Membuat dan memelihara keakraban karyawan di dalam RRI Cabang MadyaDenpasar merupakan salah satu kegiatan yang dilakukan Public Relations. Hal ini dilakukan tidak hanya untuk mencari nama saja, pada hakekatnya untuk mencari hubungan yang harmonis antara atasan dengan karyawan maupun antara sesama karywan. Dengan adanya komunikasi yang baik akan memperkecil timbulnya pertentangan sehingga dalam melakukan pekerjaan mendapatkan hasil kerja yang optimal, terlebih dalam menjaring pemasang iklan agar dapat mempertahankan dan mengembangkan RRI.

Menciptakan hubungan yang harmonis dengan seluruh karyawan RRI Cabang-Madya Denpasar merupakan tanggung jawab general manager. Tetapi hal itu tidak hanya tanggung jawab dari general manager saja, tetapi juga tanggung jawab Public Relations. Dalam hal ini Public Relations RRI Cabang MadyaDenpasar berusaha memberikan kegiatan yang mendukung terciptanya suasana akrab, harmonis, dan kekeluargaan yakni berupa: (1) Mengadakan pertemuan rutin seluruh karyawan setiap satu kali seminggu untuk membahas hasil kerja yang sudah dijalankan dengan turut serta membuat ataupun sekedar saran untuk memperbaiki beberapa segi dalam pelaksanaan kegiatan RRI Cabang Madya Denpasar, (2) Memberikan informasi kepada seluruh karyawan RRI Cabang Madya Denpasar mengenai semua kegiatan yang dilaksanakan oleh pihak RRI, informasi yang dibuat Publik Relations berupa poster-poster yang dipasang di tempat strategis, serta di depan gedung kantor karyawan, ruang tunggu tamu atau karyawan dan lain-lain, kemudian komunikasi secara langsung dengan karyawan melalui atasan masing-masing.
Hal ini dilakukan agar kesenjangan antara karyawan dengan pimpinan tidak terjadi, (3) Memberikan kepercayaan kepada karyawan atau bawahan dalam melakukan suatu pekerjaan, sehingga ada rasa saling memiliki (sense of belonging) antar karyawan dengan atasan maupun sesama karyawan. Memberikan bimbingan dan pembinaan kepada karyawan melalui kegiatan-kegiatan tertentu agar dapat meningkatkan kreativitas kerjanya, dan (4) Menerapkan disiplinan terhadap karyawan RRI Denpasar dengan cara memberikan hukuman (punishment) terhadap karyawan yang tidak disiplin dan memberikan hadiah (reward) terhadap karyawan untuk memotivasi karyawan dalam bekerja agar mendapatkan hasil kerja yang optimal.

Dalam usaha untuk menjaring pemasang iklan Public Relations menawarkan program atau program siaran acara unggulan di RRI Cabang Madya Denpasar kepada masyarakat dengan menyebarkan brosur-brosur di perusahaan-perusahaan, sekolah-sekolah dan lain-lain. Berikut adalah susunan program acara unggulan dari masing-masing program:

\section{a. Program I}

Spesifikasi Siaran

Frekuensi

: FM 88.6 MHz $1206 \mathrm{KHz}$ Power: FM $10 \mathrm{KW}$ dan 2,5 KW

Repeater : Bukit Sega dan Tamblingan Buleleng

Jam Siaran : Pkl. 05.00-24.00 WITA (Setiap hari kecuali hari raya Nyepi)

Format Stasiun : Informasi Pendidikan dan Hiburan

Jangkauan

Khalayak

: Masyarakat Bali semua usia dan strata sosial.

Jangkauan

Wilayah : Seluruh Bali dan sekitarnya

Pro I adalah program siaran RRI Denpasar yang menghadirkan berbagai macam acara hiburan dan informasi serta produk jasa siaran dengan segmen semua strata sosial masyarakat baik di bidang ekonomi, sosial, budaya dan politik.

b. Program II

Frekuensi : FM 93,4 MHz

Power : $5 \mathrm{KW}$

Jam Siaran : Pkl. 05.00-24.00 Wita 
(Setiap hari kecuali hari raya Nyepi)

Format Stasiun : Hiburan informasi

Segmentasi : Seluruh Bali dan sekitarnya

Pro II adalah program siaran RRI Denpasar yang menghadirkan berbagai macam acara tentang adat istiadat di Bali. c. Program III

Frekuensi :

Power : $5 \mathrm{KW}$

Jam Siaran : Pkl. 00.00-24.00 Wita (Setiap hari kecuali hari raya Nyepi)

Format Stasiun : $\quad$ Berita dan Wicara

Segmentasi : $\quad$ Seluruh Bali dan sekitarnya

Tabel 1 Program Siaran Pro I RRI Denpasar

\begin{tabular}{|c|c|c|}
\hline HARI & JAM SIARAN & MATA ACARA \\
\hline Senin s/d Sabtu & $\begin{array}{l}\text { Pkl. 06.10-06.30 Wita } \\
\text { Pkl. 06.30-08.00 Wita }\end{array}$ & $\begin{array}{l}\text { Galang Kangin } \\
\text { Hai Bali Kenken }\end{array}$ \\
\hline Senin s/d Jumat & $\begin{array}{l}\text { Pkl. } 09.00-10.30 \text { Wita } \\
\text { Pkl. } 10.30-12.00 \text { Wita }\end{array}$ & $\begin{array}{c}\text { Kembang Rampe } \\
\text { Dagang Gantal } \\
\text { (Relay Pro 2) }\end{array}$ \\
\hline Selasa & Pkl. 13.00 - 14.00 Wita & $\begin{array}{l}\text { Wacakan Rejeki } \\
\text { (Relay Pro 2) }\end{array}$ \\
\hline Senin, Rabu, Jumat & Pkl. $15.00-17.00$ Wita & Godang Asyik \\
\hline Selasa \& Kamis & Pkl. $15.00-17.00$ Wita & Lenggang Maco \\
\hline Selasa, Kamis, Sabtu & Pkl. $22.10-24.00$ Wita & Dibuang Sayang \\
\hline Selasa, Kamis, Sabtu & Pkl. $18.00-19.00$ Wita & $\begin{array}{l}\text { Tembang Warga } \\
\text { (Relay Pro 2) }\end{array}$ \\
\hline Minggu & Pkl. 10.00 - 19.00 Wita & Arja (Relay Pro 2) \\
\hline Sabtu & Pkl. 10.30 - 12.00 Wita & $\begin{array}{l}\text { Taman Panasar } \\
\text { (Relay Pro 2) }\end{array}$ \\
\hline
\end{tabular}

Tabel 2 Program Siaran Pro II RRI Denpasar

\begin{tabular}{ccc}
\hline HARI & JAM SIARAN & MATA ACARA \\
\hline Setiap Hari & Pkl. $06.00-06.30$ Wita & Galang Kangin \\
& Pkl. $15.00-17.00$ Wita & -08.00 Wita \\
& Pkl. $20.00-22.00$ Wita & $\begin{array}{c}\text { Hai Bali Kenken } \\
\text { Tembang Dewata } \\
\text { Lagu Nostalgia }\end{array}$ \\
\hline Senin s/d Jumat & Pkl. $10.30-12.00$ Wita & Dagang Gantal \\
\hline Selasa & Pkl. $13.00-14.00$ Wita & Wacakan Rejeki \\
\hline Selasa, Kamis, Sabtu & Pkl. $18.00-19.00$ Wita & Tembang Warga \\
\hline Minggu & Pkl. $10.00-19.00$ Wita & Arja \\
\hline Sabtu & Pkl. $10.30-12.00$ Wita & Taman Panasar
\end{tabular}




\section{Lintas Dewata}

Memberikan informasi masalah aktual dan peristiwa penting serta pernak-pernik kehidupan selama 30 menit (pukul 06.30 - 07.00 Wita setiap hari).

\section{Dialog Pagi "Hai Bali Kenken"}

Acara interaktif yang membahas berbagai persoalan yang menjadi perhatian publik atau menyentuh kepentingan masyarakat dan menjelaskan masalah-masalah aktual serta sekaligus memperoleh masukan dari masyarakat. Dapat diikuti setiap hari selama 45 menit pukul 07.15 - 08.00 Wita.

\section{Indonesia Menyapa}

Disiarkan setiap Senin - Sabtu selama 60 menit pukul 09.00 - 10.00 Wita langsung dari stasiun-stasiun RRI se-Indonesia bergantian.

\section{Berita Ibu Kota / Berita Siang}

Menyajikan berbagai berita informasi masalah aktual. Disiarkan setiap hari selama 15 menit pukul $11.00-11.15$ Wita.

\section{Warta Berita "Lintas Dewata Siang"}

Menyajikan informasi yang aktual dan terkini disiarkan setiap hari selama 25 menit pukul 14.30 - 14.55 Wita.

\section{Warta Berita Bahasa Bali}

Menyajikan informasi dan masalah aktual bagi masyarakat Bali atau yang ingin belajar Bahasa Bali, disiarkan setiap hari Senin - Sabtu pukul 18.00 - 18.15 Wita.

\section{Warta Berita "Bianglalah"}

Menyajikan berbagai informasi dan masalah aktual bagi masyarakat Bali dan bagi mereka yang ingin belajar Bahasa Bali yang disiarkan setiap hari minggu selama 25 menit pukul 18.00 -18.25 Wita.

\section{Ikhtisar Berita}

Menyajikan informasi peristiwa menonjol dalam sepekan kepada masyarakat, disiarkan setiap hari Minggu selama 25 menit pukul 20.30 -20.55 Wita.

\section{Dialog Interaktif "Gelar Wicara Budaya"}

Siaran langsung interaktif yang memberikan pemahaman tentang kompleksitas budaya yang ada di masyarakat Bali dengan tujuan untuk meningkatkan apresiasi masyarakat terhadap seni dan budaya yang merupakan bagian hidup sehari-hari masyarakat Bali. Disiarkan setiap hari Jumat akhir bulan selama 2 jam pukul 16.00 -18.00 Wita.

Pro III adalah tabel program siaran RRI Denpasar yang menyajikan berita terkini dan aktual kepada masyarakat Bali.

d. Paradise FM

Frequency

: FM 100,9 MHz
Power

: $5 \mathrm{KW}$

Frequency Reach

: Island of Bali

Station Format

: Music and

Tourism Info

Listeners Demographics:

- Professionals

- English speaking Indonesians, expatriates living on the island and local community who enjoy nostalgic songs.

- Men and Women aged 25's to 60's with buying power/ disposable income varied array of consuming needs. Desire for relation easy listening music.

- Average income per month above Rp. 2.500.000,-

- Majority in the tourism industry, Hotels, Travel Agents, Travel Operators, Banks, Rental Cars, Insurance, Furniture, Export and Import Business etc.

\section{Paradise FM}

The Only English Radio Station in Bali

Daily from 6.00 am Until 10.00 pm

Prime Time:

$08.00-11.00 \mathrm{am}$

$12.00-2.00 \mathrm{pm}$

$5.00-00 \mathrm{pm}$

\section{"Good Morning Bali"}

Daily from 08.00 - 11.00 am Our announcer will Join you with Internasional and local news in English, Tourist information, Joke, Music request And Great music to get your Day off to a good start

\section{"Sunset Program"}

Daily from $5.00-8.00 \mathrm{pm}$ accompanying you to Welcome the beautiful sunset on the island While listening to information on different topics And discussions bringing you to enjoy the evening

Program

ALL - English - Program with special segments:

8.00 - 11.00 am Good Morning Bali - Daily

$5.00-8.00$ pm Daily - Sunset Program, consist of topics as follows:

Monday

: Keep Fit

Tuesday

: Woman's World

Wednesday

: Biz Talk

Thusday

: Profile

Friday

: What's Up

Saturday

Sunday

: Did You Know

: Men's Toy

Paradise FM adalah program acara yang menyajikan tentang musik dan informasi dunia pariwisata dalam bahasa Inggris, dan ditujukan kepada professional, berkomunikasi dengan 
menggunakan bahasa Inggris, para wisatawan dan pencinta lagu-lagu nostalgia.

Selain menyebarkan brosur-brosur Program Public Relation RRI Denpasar juga memasang spanduk dan Baliho ditempat yang strategis dan juga menyebarkan leaflet, agar dapat menarik simpati atau minat masyarakat untuk memasangkan iklannya.
Bila masyarakat atau pengguna jasa ingin memsang iklannya di RRI Cabang Madya Denpasar, tentunya mereka terlebih dulu harus mengetahui beberapa biaya untuk menyewa jasa siaran dan jasa non siaran, maka Public Relation RRI Denpasar menawarkan rincian tarif jasa siaran dan non siaran yang dapat dilihat dalam Tabel 3 berikut.

Tabel 3 Tarif Jasa Siaran RRI Denpasar Tahun 2011

\begin{tabular}{|c|c|c|c|}
\hline NO & BENTUK SIARAN & $\begin{array}{l}\text { TARIF / SEKALI } \\
\text { SIARAN (Rp) }\end{array}$ & KETERANGAN \\
\hline 1 & Spot Iklan & 30.000 & 60 detik \\
\hline 2 & Adlib / Iklan Baca & 25.000 & 60 detik \\
\hline 3 & Time Signal & 100.000 & 30 detik \\
\hline \multirow[t]{5}{*}{4} & Sponsor : & & \\
\hline & a. Siaran Olah Raga & 2.000 .000 & 2 jam \\
\hline & b. Siaran Pagelaran Musik & 1.000 .000 & 1 jam \\
\hline & c. Siaran Arja & 3.000 .000 & 4 jam \\
\hline & d. Siaran Sandiwara & 1.500 .000 & 30 menit \\
\hline 5 & Join Production & 350.000 & Per Item \\
\hline 6 & Interaktif & 1.000 .000 & 1 jam (studio) \\
\hline 7 & Tal Show & 2.500 .000 & 1 jam (L.studio) \\
\hline 8 & Lintas Sekoral & 1.500 .000 & $1 \mathrm{jam}$ \\
\hline 9 & Berita Bisnis & 100.000 & Per Item \\
\hline 10 & Berita Non Bisnis & 50.000 & 2 menit \\
\hline 11 & Iklan Layanan Masyarakat & 17.500 & 3 menit \\
\hline 12 & Report On The Spot & 250.000 & 60 detik \\
\hline 13 & Obrolan & 500.000 & 3 menit \\
\hline 14 & Kuis (Hadiah dari sponsor) & 1.000 .000 & 60 menit \\
\hline 15 & Advetorial & 300.000 & 60 menit \\
\hline 16 & Majalah Udara & 750.000 & 30 menit \\
\hline 17 & Pengumuman Lelang & 750.000 & 60 menit \\
\hline
\end{tabular}

Tarif non jasa siaran yang ditawarkan oleh RRI adalah penyewaan fasilitas yang ada di RRI Denpasar kepada masyarakat dengan harga yang sangat relatif sesuai dengan barang atau fasilitas apa yang dibutuhkan. Sedangkan tarif jasa siaran adalah penyewaan jasa siaran oleh pengguna jasa untuk memasangkan iklannya di RRI Cabang Madya Denpasar, sesuai dengan harga dari jenis iklan yang akan disiarkan.

Di atas kita sudah melihat cara-cara seperti apa yang ditawarkan oleh Public Relation dalam rangka menjaring pemasang iklan di RRI Cabang Madya Denpasar. Agar para pengguna jasa merasa puas dengan pelayanan RRI Cabang Madya Denpasar. Berikut ini adalah kiat-kiat yang dilakukan para karyawan 
Tabel 4 Tarif Jasa Non Siaran RRI Denpasar Tahun 2011

\begin{tabular}{|c|c|c|c|}
\hline NO & FASILITAS YANG DISEWAKAN & TARIF (Rp) & KETERANGAN \\
\hline 1 & Panggung Terbuka (Open Stage) & 750.000 & Per jam \\
\hline 2 & Ruang Pertemuan & 250.000 & Per jam \\
\hline 3 & Studio Rekaman & 200.000 & Per jam \\
\hline 4 & Perangkat Band & 2.000 .000 & \\
\hline 5 & Organ Tunggal & 1.000 .000 & \\
\hline 6 & Sound System & 2.000 .000 & \\
\hline 7 & Gambelan & 2.500 .000 & \\
\hline 8 & Ruang Kantor & 500.000 & Per bulan \\
\hline 9 & Lokasi Biliboard & 3.500 .000 & Per 6 bulan \\
\hline 10 & Tower & 3.000 .000 & Per bulan \\
\hline 11 & Rekaman Luar Studio & 500.000 & Per jam \\
\hline 12 & Lokasi ATM & 10.000 .000 & Per tahun \\
\hline 13 & Penyewaan Halaman RRI & 1.000 .000 & Per kegiatan \\
\hline \multirow[t]{8}{*}{14} & Pentas Kesenian : & & \\
\hline & a. Arja & 5.000 .000 & \\
\hline & b. Topeng Prembon & 3.500 .000 & \\
\hline & c. Bondres RRI & 2.500 .000 & \\
\hline & d. Taman Panasar & 2.000 .000 & \\
\hline & e. Pasantian & 1.000 .000 & \\
\hline & f. Joged Bumbung & 1.000 .000 & \\
\hline & g. Wayang Kulit Parwa & 1.500 .000 & \\
\hline \multirow[t]{9}{*}{15} & $\begin{array}{l}\text { h. Wayang Kulit Ramayana } \\
\text { Tabuh : } \\
\text { a. Baleganjur } \\
\text { b. Gong Kebyar }\end{array}$ & $\begin{array}{l}2.000 .000 \\
1.500 .000 \\
2.000 .000\end{array}$ & \\
\hline & c. Semar Pagulingan & 2.000 .000 & \\
\hline & d. Palegongan & 2.000 .000 & \\
\hline & e. Gong Suling & 1.000 .000 & \\
\hline & f. Gender & 600.000 & \\
\hline & g. Angklung & 1.000 .000 & \\
\hline & h. Rindik & 500.000 & \\
\hline & i. Joged & 500.000 & \\
\hline & j. Lelambatan & 1.000 .000 & \\
\hline 16 & Produksi Spot & 500.000 & Durasi 60 detik \\
\hline
\end{tabular}


RRI Denpasar untuk memberikan pelayanan yang maksimal terhadap pengguna jasa berupa melayani permintaan klien sesuai dengan kebijakan RRI Cabang Madya Denpasar, negosiasi harga yang dapat diterima oleh klien, menyiarkan iklan sesuai dengan permintaan klien, mengadakan pertemuan dan koordinasi terhadap komplein yang datang dari klien. Demikian juga memberikan kompensasi jika kesalahan datang dari pihak RRI Cabang Madya Denpasar, dan memberikan pelayanan yang ramah terhadap klien.

Faktor pendukung Public Relations dalam menjaring pemasang iklan pada RRI Cabang Madya Denpasar dianataranya (1) Tersedianya Sarana Transportasi bagi Public Relations. Dalammenjalankan tugasnya, RRImenyediakan sarana transportasi bagi Public Relations. Hal ini dilakukan untuk meningkatkan kinerja karyawan dalam melaksanakan tugasnya. Sarana ini juga untuk memperlancar kegiatan di luar perusahaan baik yang lokasinya jauh maupun yang sekitar perusahaan, (2) Adanya dukungan dan kerjasama yang baik dari karyawan dengan ikut memberikan pelayanan yang baik pada pelanggan atau masyarakat pendengar. Dengan adanya dukungan dari semua karyawan akan terciptanya suatu kerja sama yang baik dari seluruh karyawan yang ada di RRI baik diluar maupun di dalam perusahaan yang menyangkut kegiatan-kegiatan perusahaan. Adanya suasana kekeluargaan yang harmonis yang diciptakan internal perusahaan sehingga mendukung kegiatan Public Relations dengan baik dan dapat mencapai hasil yang optimal, dan (3) Coverege Area atau jangkauan pancaran siaran RRI yang cukup luas. Satelit-satelit penerima pancaran siaran terletak dimana-mana termasuk di desa yang sangat kecil sekalipun, mengingat RRI adalah radio Pemerintah dan sudah sangat lama didirikan. Jadi tidaklah sulit bagi RRI untuk menyampaikan pesan kepada masyarakat, karena satelit penerima pancaran sudah ada dimana-mana.

Sedangkan faktor penghambat Public Relations dalam menjaring pemasang iklan pada RRI Cabang Madya Denpasar diantaranya (1) Minimnya dana perawatan sarana dan prasarana. Alat-alat yang digunakan oleh RRI Denpasar seperti peralatan elektronik yaitu komputer adalah alat-alat yang sudah tua yang membutuhkan dana perawatan yang cukup. Bila terjadi kerusakan pada alat elektronik dan tidak bisa diperbaiki karena dana perawatan tidak cukup maka akan menghambat kelancaran tugas dari karyawan, (2) Program pengembangan serta pendidikan latihan untuk meningkatkan sumber daya manusia belum dilaksanakan secara terpadu, (3) Masih terbatasnya pengetahuan dan kemampuan tim kerja Public Relations dalam melaksanakan tugas dan tanggung jawab, dan (4) Minimnya kemampuan pengetahuan, keterampilan yang dimiliki karyawan sehingga dapat menghambat pelaksanaan kegiatan.

Untuk mengatasi hal ini karyawan diberikan modal pengetahuan, keterampilan dan wawasan yang cukup tentang iklan yang bagus sehingga terciptanya karyawan yang berpotensi. Selain itu juga karyawan diberi pengarahan dan bimbingan mengenai fungsi dan tugas, tujuan dan manfaat dari tugas RRI sehingga para karyawan memiliki bekal serta tanggung jawab guna meningkatkan kualitas kinerja kerja para karyawan di RRI Cabang Madya Denpasar.

Kesimpulan analisis data yang didapat selama melakukan penelitian di RRI Cabang Madya Denpasar adalah peranan Public Relations sangatlah dibutuhkan dalam suatu perusahaan, apalagi di dalam sebuah stasiun radio yang begitu banyak saingan. Cara-cara Public Relations dalam menjaring pemasang iklan sudah dikatakan cukup berhasil, hal ini terbukti dalam saut bulan RRI Cabang Madya Denpasar menerima $2-3$ klien yang ingin memasangkan iklannya di RRI Cabang Madya Denpasar dengan masa kontrak yang cukup lama. Kita juga dapat melihat pada tabel 4.2 mengenai data klien jasa siaran atau klien yang memasangkan iklannya di RRI Cabang Madya Denpasar, dari bulan Maret 2010 sampai bulan Maret 2011 terbilang ada 25 perusahaan yang terikat kontrak dengan RRI Denpasar, ada yang masa kontraknya sudah berakhir tetapi ada juga yang masa kontraknya sampai bulan Desember 2011.

Melalui cara-cara yang dilakukan oleh Public Relations yaitu menyebarkan brosur dan leaflet serta memasangkan spanduk dan baliho sehingga dapat menarik simpati masyarakat untuk memasangkan iklannya. Serta memberikan pelayanan yang sebaik-baiknya kepada klien agar dapat terciptanya suasana yang harmonis antara pengguna jasa dan RRI Cabang Madya Denpasar. Public Relations RRI Cabang Madya Denpasar juga berusaha untuk memelihara kerja sama yang baik antara karyawan dan atasan maupun antara sesama karyawan, agar di dalam melakukan suatu pekerjaan dapat mencapai hasil yang optimal. 
Sedangkan untuk kendala-kendala yang dialami oleh Public Relations RRI Cabang Madya Denpasar tidak dapat dihindari mengingat begitu minimnya dana perawatan sarana dan prasarana serta rendahnya mutu SDM yang ada. Mungkin hal ini tidak hanya terjadi di RRI Cabang Madya Denpasar saja tetapi juga bisa terjadi di stasiun radio lainnya. Pembahasan

Radio Republik Indonesia Cabang Madya Denpasar membutuhkan peningkatan dan kualitas dari cara kerja Public Relationsnya, agar dapat mempertahankan dan mengembangkan RRI Cabang Madya Denpasar menjadi sebuah stasiun radio yang lebih maju dan berhasil untuk masa yang akan datang. Sarana dan prasarana untuk membantu Publik Relations dalam melakukan tugasnya harus lebih memadai, mengingat pekerjaan Public Relations yang cukup sulit. Public Relations harus melakukan persaingan dengan stasiun radio lainnya dalam menarik simpati dan minat masyarakat untuk memasangkan iklan. Tidak hanya sarana dan prasarana saja yang lebih diperhatikan, tetapi juga kualitas SDM para karyawan yang harus lebih ditingkatkan agar dapat menghasilkan pekerjaan yang maksimal.

Disamping itu juga Public Relations RRI Cabang Madya Denpasar harus mulai menyiapkan cara-cara kerja yang baru dalam menarik simpati dan minat masyarakat. Sejauh ini segala sarana seperti elektronik, transportasi serta kualitas SDM dari seluruh karyawan sudah lebih ditingkatkan dan diperhatikan. Mudah-mudahan Public Relations RRI Cabang Madya Denpasar lebih bekerja keras lagi dalam menjaring pemasang iklan, agar tidak menjadi stasiun radio yang tertinggal dari stasiun radio lainnya.

\section{SIMPULAN}

Setelah menyusun dan membahas keseluruhan peranan Public Relations dalam menjaring pemasang iklan pada RRI Cabang MadyaDenpasar,makadapatdisimpulkan bahwa peranan dan fungsi Public Relations dilakukan oleh Divisi Pemasaran dan Pembangunan Usaha. Public Relations berusaha menciptakan hubungan kerjasama yang harmonis antara atasan dan karyawan maupun antara sesama karyawan, melalui komunikasi terhadap semua pihak yang berkaitan secara langsung di RRI Cabang Madya - Denpasar. Public Relations berusaha menjalankan langkah-langkah atau cara kerja yang maksimal agar dapat menarik minat dan simpati masyarakat untuk memasangkan iklannya di RRI Cabang Madya - Denpasar. Serta memberikan pelayanan yang sebaik-baiknya kepada pengguna jasa agar mereka merasa puas, sehingga dapat terjalinnya hubungan kerja sama yang harmonis dan profesional antara RRI Cabang Madya Denpasar dan konsumen.

Dari hasil penelitian yang dilakukan keberadaan Public Relations di RRI Cabang Madya Denpasar sangat berperanan, dimana dapat terciptanya hubungan yang harmonis antar karyawan di dalam perusahaan dan juga dapat terjalinnya hubungan kerja sama yang baik antara pengguna jasa dan RRI Denpasar. Cara kerja yang digunakan Public Relations untuk menarik simpati masyarakat untuk memasangkan iklannya di RRI Denpasar cukup berhasil mengingat cukup banyaknya iklan yang masuk.

Adanya faktor pendukung yang membantu public relation dalam menjalankan tugas dan pekerjaannya, yang dapat menghasilkan suatu pekerjaan yang lebih baik. Tetapi juga ada faktor penghambat bagi Public Relations dalam menjalankan fungsi dan tugasnya, hal ini tidaklah menjadi sesuatu yang harus ditakutkan karena dengan bekerja sama semua dapat diatasi dengan baik.

Dari hasil penelitian yang dilakukan di RRI Cabang Madya - Denpasar khususnya Divisi PPU yang merangkap sebagai Public Relations, ada beberapa saran yang mungkin dapat dilakukan untuk kemajuan RRI sebagai salah satu usaha yang bergerak di bidang penyiaran, diantaranya:

Oleh karena adanya dukungan dan kerjasama yang baik dari seluruh karyawan merupakan faktor pendukung bagi Public Relations, maka RRI perlu melakukan sosialisasi dan penggiatan seluruh karyawan.

Oleh karena minimnya dana perawatan sarana dan prasarana maka menghambat pelaksanaan kerja Public Relations, jadi RRI Cabang Madya-Denpasar perlu membahas mengenai biaya tersebut agar dananya dapat ditambah untuk mengganti semua peralatan yang tidak layak dipakai.

Oleh karena rendahnya mutu SDM yang ada, maka RRI Cabang Madya-Denpasar harus memberikan pelatihan yang memadai kepada karyawan dan juga memberikan pengarahan mengenai tugas dan fungsi masing-masing terutama di dalam menjaring pemasang iklan. 


\section{DAFTAR PUSTAKA}

Astrid, S. S. (1974). Komunikasi dalam teori dan praktek. Bandung: Bina Cipta.

Djanaid, D. (1992). Public Relations dalam teori dan praktek. Edisi VII (Revisi) Malang: Indopurels Training

Effendy, O. U. (1986). Ilmu Komunikasi teori dan praktek. Bandung: Remaja Karya.

Effendy, O. U. (1999). Hubungan masyarakat. Bandung: Rosda Karya.

Effendy, O. U. ( 1990). Ilmu Komunikasi. Bandung: Citra Aditya Bakti.
Jalaluddin, R. (1991). Metode penelitian komunikasi. Bandung: Remaja Rosada Karya.

Meinanda, T. (1980). Dasar-dasar Public Relations. dalam tanya jawab. Bandung: Armice.

Oemi, A. (1977). Dasar-dasar Public Relations. Bandung: Alumni.

Soemirat, S. \& Ardianto, E. (2002). Dasardasar Public Relations. Bandung: Remaja Rosda Karya.

Widjaja, A.W. (1988). Ilmu Komunikasi (pengantar studi). Jakarta: Bina Aksara. 